\title{
PERUBAHAN COULOMB STRESS AKIBAT GEMPABUMI LAUT MALUKU 7 JANUARI 2019
}

\author{
Pricilia Windy Siwi ${ }^{1}$, Sesar Prabu Dwi Sriyanto ${ }^{2}$, Anneke T. Rondonuwu ${ }^{1}$, dan Patricia M. Silangen ${ }^{1}$ \\ 1Jurusan Fisika, FMIPA, Universitas Negeri Manado, ${ }^{2}$ Stasiun Geofisika Manado \\ e-mail : sesar.sriyanto@bmkg.go.id
}

\begin{abstract}
Abstrak. Gempabumi dengan Mw 6,6 mengguncang wilayah Laut Maluku pada tanggal 7 Januari 2019. Gempabumi yang memiliki koordinat episenter pada $2,50^{\circ} \mathrm{LU}$ dan $126,70^{\circ} \mathrm{BT}$ dengan kedalaman $34,5 \mathrm{~km}$ ini diikuti oleh gempabumi-gempabumi susulan yang tercatat hingga 2 minggu setelah gempabumi utama. Penelitian ini dilakukan untuk mengetahui sebaran perubahan Coulomb stress akibat gempabumi tersebut. Selain itu, dianalisis pula hubungan sebaran perubahan Coulomb stress tersebut dengan lokasi gempabumi susulan. Penelitian ini menggunakan data mekanisme fokus gempabumi yang diunduh dari basis data Global Centroid Moment Tensor (Global CMT). Perhitungan perubahan nilai Coulomb stress dihitung menggunkan software Coulomb 3.3. Hasil penelitian menunjukkan bahwa gempabumi ini menyebabkan perubahan Coulomb stress dalam rentang $-0,5$ hingga 0,5 bar tidak hanya di lokasi episenter namun juga di daerah sekitarnya. Sebaran perubahan Coulomb stress secara horizontal membentuk pola 2 lokus negatif dan 2 lokus positif dengan lokasi episenter berada di lokus negatif. Hal ini menunjukkan telah terjadi pelepasan tekanan batuan melalui peristiwa gempabumi. Lokasi episenter gempabumi susulan sebagian besar berada di area lokus positif dimana terjadi peningkatan tekanan batuan yang diperkirakan sebagai pemicu terjadinya gempabumi susulan.
\end{abstract}

Kata Kunci: gempabumi Laut Maluku; gempabumi susulan; perubahan Coulomb stress

\begin{abstract}
On January 7, 2019, an earthquake happened in the middle of the Molucca Sea with the magnitude of $\mathrm{Mw}$ 6.6. This earthquake located in latitude $2.50 \mathrm{~N}$ and longitude $126.70 \mathrm{E}$ with the focal depth about $34.5 \mathrm{~km}$, followed by aftershocks located around the mainshock epicenter that recorded until two weeks after the mainshock. This study aims to know the spatial distribution of Coulomb stress change caused by the mainshock. Furthermore, the relationship between the spatial distribution of Coulomb stress change and the distribution of aftershocks epicenter was analyzed too. The parameter of earthquake source mechanism obtained from the Global Centroid Moment Tensor (Global CMT) database, processed using Coulomb version 3.3.1 software. The result shows that this earthquake triggers the change of Coulomb stress in the range of -0.5 until 0.5 bar. The change of Coulomb stress not only placed in the mainshock epicenter but also spread around the epicenter. Spatial distribution of stress change horizontally forms four lobes that contain two positive lobes and two negative lobes. Mainshock epicenter located in negative stress change, which indicated there had been a release of rock stress through the earthquake. Meanwhile, the aftershocks mostly located in positive stress change, which is thought to trigger a subsequent earthquake.
\end{abstract}

Keywords: Molucca sea earthquake; aftershocks; Coulomb stress change

\section{PENDAHULUAN}

Pada tanggal 7 Januari 2019 tepat pukul 01:27 WITA terjadi gempabumi yang berkekuatan Mw 6,6 di tengah Laut Maluku. Berdasarkan data United States Geological Survey (USGS, 2019), gempabumi ini memiliki koordinat episenter pada $2,50^{\circ} \mathrm{LU}$ dan $126,70^{\circ}$ BT dengan kedalaman $34,5 \mathrm{~km}$. Mekanisme sumber gempabumi ini berupa patahan naik dengan parameter bidang sesar strike $16^{\circ}$, dip $33^{\circ}$ dan rake $78^{\circ}$.
Secara tektonik, di tengah Laut Maluku terdapat fitur tektonik berupa punggungan (ridge) yang dikenal dengan nama punggungan TalaudMayu (Zhang dkk., 2017). Fitur tektonik yang memanjang arah baratdaya-timur laut ini menjadi lokasi dengan tingkat aktivitas seismik yang tinggi (Sriyanto dkk., 2019). Hal ini dibuktikan dengan hasil catatan kegempaan yang menunjukkan telah terjadi 15 kali gempabumi dengan magnitudo lebih dari 7,0 selama kurun waktu 1900-2019 (USGS, 2020). 
Kejadian gempabumi merupakan akibat dari adanya pelepasan tegangan batuan yang saling menekan. Ketika batas elastisitas batuan terlampaui maka terjadi pelepasan energi sebagai gempabumi akibat ketidakmampuan batuan menahan tekanan. Hal ini akan menyebabkan perubahan tingkat tegangan batuan baik di lokasi episenter maupun di daerah sekitarnya. Salah satu metode untuk melihat sebaran tegangan batuan akibat gempabumi adalah metode perubahan Coulomb stress (Weatherley, D $K, 2006)$.

Berdasarkan data pengamatan Badan Meteorologi Klimatologi dan Geofisika (BMKG, 2019), gempabumi Laut Maluku 7 Januari 2019 diikuti oleh gempabumi susulan sebanyak 90 kali dalam kurun waktu 2 minggu hingga tanggal 21 Januari 2020. Magnitudo tertinggi pada rangkaian gempabumi susulan tersebut adalah 5,4, sedangkan magnitude terendah adalah 3,0 dengan rata-rata 3,7 . Untuk mengetahui hubungan pemicuan antara gempabumi utama dengan gempabumi susulan, maka pada studi ini dilakukan analisa sebaran perubahan Coulomb stress secara spasial dan ditinjau kaitannya dengan lokasi gempabumi susulan.

\section{METODOLOGI}

(Harris, 1998) dalam (Wu dkk., 2016) menjelaskan bahwa Coulomb stress adalah selisih antara tegangan geser (shear stress) $(\tau)$ dengan kekuatan gesekan (frictional strenght) $(\tau f)$. Pada persamaan (1) berikut ditunjukkan rumusan matematis dari Coulomb stress (CS):

$$
\mathrm{CS}=\tau-\tau f
$$

Tegangan geser didefinisikan sebagai tegangan yang berada sejajar atau menyinggung suatu permukaan, sedangkan kekuatan gesekan adalah batas kekuatan suatu permukaan untuk menahan gesekan sebelum pecah. Pada kasus gempabumi, dua blok batuan yang saling bergerak pada arah yang berbeda akan menyebabkan berkembangnya bidang kontak yang disebut bidang sesar atau bidang patahan. Pada bidang kontak ini tegangan geser akan terus meningkat seiring berjalannya waktu. Apabila kekuatan gesekan permukaan bidang sesar tersebut telah terlampaui oleh tegangan geser, maka terjadi pecahnya batuan yang dikenal dengan gempabumi. Berdasarkan kriteria Coulomb-Mohr failure, pecahnya batuan ini tidak hanya disebabkan oleh faktor tegangan geser saja namun juga kombinasi dengan tegangan normal ((Dowling dkk., 2012) dalam (Wu dkk., 2016)). (Wu dkk., 2016) menjelaskan bahwa rumusan kekuatan gesekan adalah sebagai berikut:

$\tau f=s-\mu(\sigma n-p)$

dengan $s$ adalah kohesi, $\mu$ adalah koefisien gesekan internal, $\sigma n$ adalah tegangan normal pada bidang patahan, dan $p$ adalah tekanan pori. Dari persamaan (2) tersebut maka persamaan (1) dapat diubah menjadi bentuk sebagai berikut:

$\mathrm{CS}=\tau-s-\mu(\sigma n-p)$

Selanjutnya, dari persamaan (3) tersebut bisa diturunkan rumusan perubahan Coulomb stress $(\Delta C S)$ di bidang patahan sebagai berikut:

$\Delta \mathrm{CS}=\Delta \tau+\mu(\Delta \sigma n-\Delta p)$

dengan $\Delta \tau$ adalah tegangan geser searah dengan slip pada bidang sesar penerima. $\Delta \sigma n$ adalah perubahan stres normal, $\Delta p$ adalah perubahan tekanan pori, dan $\mu$ adalah koefisien gesekan. Rumusan (4) tersebut dapat diubah menjadi bentuk sesuai dengan persamaan (5) dengan mengasumsikan medianya homogen isotropik dan perubahan tekanan pori berkaitan dengan tegangan normal (Wu dkk., 2015):

$\Delta \mathrm{CS}=\Delta \tau+\mu^{\prime} \Delta \sigma$

dengan $\mu^{\prime}$ didefinisikan sebagai $\mu^{\prime}=\mu(1-\beta)$, di mana $\beta$ adalah koefisien Skempton yang nilainya antara 0 dan 1. Modulus geser, rasio Poisson, dan koefisien gesekan dalam perhitungan metode ini diasumsikan masing-masing bernilai 3,2 x $10^{5}$ bar, 0,25, dan 0,4 (King dkk, 1994 dalam Madlazim, 2015). Perhitungan perubahan Coulomb stress dalam ruang setengah elastis akibat slip pada bidang patahan berbentuk persegi ini menggunakan perangkat lunak Coulomb 3.3. (Toda dkk., 2011) 
Bidang sesar dengan bentuk persegi dimodelkan berdasarkan persamaan Scaling Law yang mengatur hubungan luasan bidang sesar dengan nilai magnitudo gempabumi. Persamaan Scaling Law yang digunakan pada studi ini menggunakan hasil penelitian (Wells dan Coppersmith, 1994) untuk tipe patahan naik, dengan rumusan matematis sebagai berikut:

$\log L=0,58 M w-2,42$

$\log \mathrm{W}=0,41 \mathrm{MW}-1,61$

dengan L, W, dan Mw masing-masing adalah panjang patahan, lebar patahan, dan magnitudo gempabumi.

Lokasi episenter gempabumi 7 Januari 2019 yang terletak di koordinat $2,50^{\circ} \mathrm{LU}$ dan $126,70^{\circ} \mathrm{BT}$ ini menjadi fokus area penelitian. Untuk mengetahui perubahan coulomb stress akibat gempabumi ini secara spasial maka area penelitian tidak hanya berada di episenter melainkan diperluas hingga rentang koordinat lintang $0,50^{\circ} \mathrm{LU}-4,50^{\circ} \mathrm{LU}$ dan koordinat bujur $124,70^{\circ} \mathrm{BT}-128,70^{\circ} \mathrm{BT}$. Pada Gambar 1 berikut ditunjukkan peta daerah penelitian beserta lokasi episenter gempabumi utama dan gempabumi susulan.

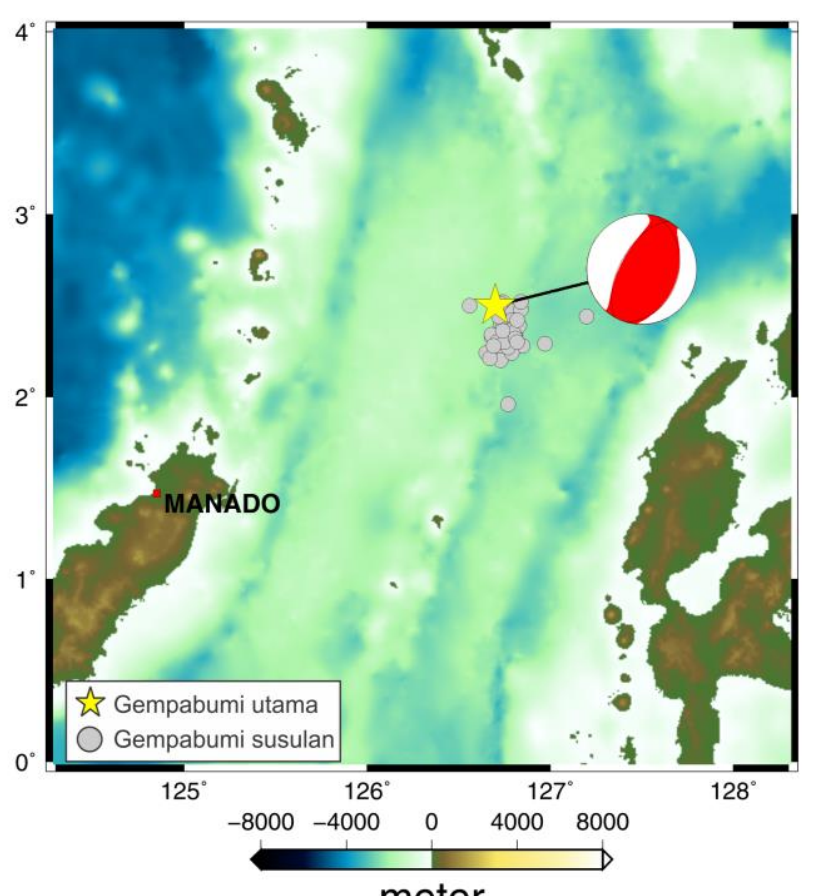

meter
Gambar 1. Lokasi episenter gempabumi utama dan gempabumi susulan.

Penelitian ini menggunakan data mekanisme fokus sumber gempabumi sebagai data masukan dalam pengolahan dan perhitungan nilai Coulomb stress. Data mekanisme sumber ini diambil dari katalog gempabumi Global Centroid Moment Tensor (Global CMT) melalui alamat website https://www.globalcmt.org/ (Ekström dkk., 2012). Data parameter mekanisme sumber gempabumi Laut Maluku 7 Januari 2019 yang diunduh dari Global CMT dapat dilihat pada Tabel 1. Sementara itu, untuk data parameter gempabumi susulan diperoleh dari basis data gempabumi (BMKG, 2019) melalui alamat website http://repogempa.bmkg.go.id/.

Tabel 1. Parameter mekanisme sumber gempabumi laut Maluku 7 Januari 2019

\begin{tabular}{cccc}
\hline & \multicolumn{4}{c}{ Parameter Bidang Sesar } \\
\cline { 2 - 4 } & $\begin{array}{c}\text { Strike } \\
\left({ }^{\circ}\right)\end{array}$ & $\begin{array}{c}\text { Dip } \\
\left(^{\circ}\right)\end{array}$ & $\begin{array}{c}\text { Rake } \\
\left(^{\circ}\right)\end{array}$ Focal \\
\hline Nodal 1 & 16 & 33 & 78 \\
\hline Nodal 2 & 210 & 58 & 98 \\
\hline
\end{tabular}

\section{HASIL DAN PEMBAHASAN}

Setelah dilakukan proses pengolahan, didapatkan distribusi perubahan Coulomb stress dari gempabumi utama 7 Januari 2019 yang bervariasi secara spasial. Pada Gambar 2 dan Gambar 3 ditunjukkan bahwa terjadi perubahan Coulomb stress bernilai negatif atau terjadi penurunan tegangan batuan di lokasi bidang sesar. Tegangan batuan di area bidang patahan menurun karena telah dilepaskan dalam bentuk gempabumi.

Secara horizontal, distribusi perubahan Coulomb stress tampak terdapat 2 lobus negatif yang menyebar secara tegak lurus terhadap bidang sesar dan 2 lobus positif yang tampak menyebar searah dengan bidang sesar. Lobus negatif tampak dominan menyebar arah barat laut-tenggara di sekitar bidang sesar hingga kurang lebih 140 km, yang mencapai Pulau Halmahera bagian utara di 
sebelah timur dan Kepulauan Siau Tagulandang Biaro di sebelah barat. Sementara itu, lobus positif menyebar pada arah timur laut-baratdaya hingga sekitar $40 \mathrm{~km}$. Gambar 2 menunjukan distribusi perubahan Coulomb stress yang disebabkan oleh gempabumi 7 Januari 2019 secara horizontal.

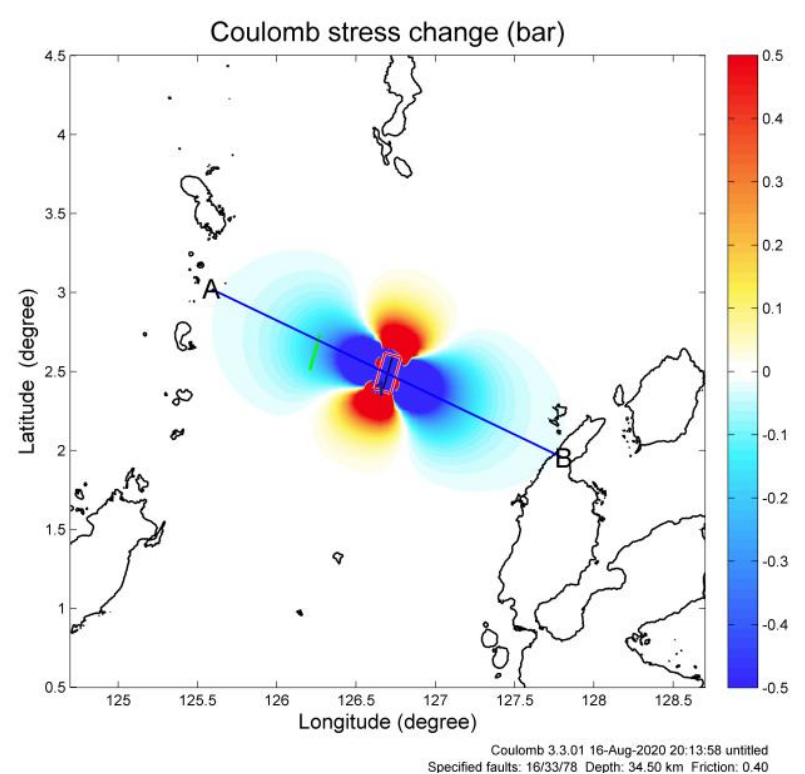

Gambar 2. Distribusi perubahan Coulomb stress gempabumi 7 Januari 2019 secara horizontal

Apabila ditinjau secara vertikal, perubahan tegangan Coulomb positif gempabumi 7 Januari 2019 menyebar hingga pada kedalaman sekitar 100 $\mathrm{km}$, sedangkan perubahan tegangan Coulomb bernilai negatif terdistribusi lebih dalam hingga mencapai kedalaman sekitar $150 \mathrm{~km}$. Perubahan tegangan Coulomb secara vertikal hasil irisan melintang sepanjang garis A-B pada Gambar 2 dapat dilihat pada Gambar 3 berikut.

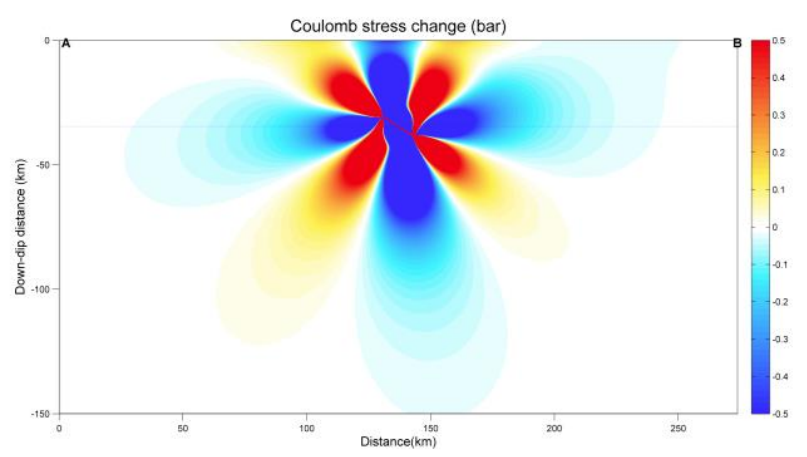

Gambar 3. Distribusi perubahan Coulomb stress gempabumi 7 Januari 2019 secara vertikal hasil irisan melintang

Pada gambaran secara vertikal yang tegak lurus terhadap arah strike, dapat dilihat sebaran perubahan tegangan Coulomb setelah gempabumi memiliki 8 lobus dengan 4 lobus positif dan 4 lobus negatif. Sudut rake gempabumi dengan nilai $78^{\circ}$ mengindikasikan bahwa tipe pergerakan patahan ini dominan naik sehingga menyebabkan terdapat 2 lobus positif di ujung garis patahan sebelah kiri atas dan kanan bawah. (King dkk., 1994) menjelaskan bahwa perubahan tegangan geser yang merupakan salah satu komponen pada perubahan Coulomb stress menyebabkan peningkatan tegangan di ujung arah pergerakan patahan. Sementara itu, 2 lobus positif lain disebabkan oleh faktor perubahan tegangan normal efektif yang arahnya tegak lurus terhadap bidang patahan (King dkk., 1994).

Perubahan Coulomb stress erat kaitannya dengan distribusi gempabumi susulan. Sebaran lokasi gempabumi susulan tidak jauh dari lokasi gempabumi utama. Pola sebaran gempabumi susulan mengikuti pola perubahan Coulomb stress. Apabila ditinjau secara horizontal, sebaran episenter gempabumi susulan dominan berada di sebelah tenggara bidang patahan, seperti yang ditunjukkan pada Gambar 4. Dari sisi ini sebagian besar gempabumi susulan terlihat berada di bagian perubahan Coulomb stress negatif. Untuk melihat lokasi sebaran gempabumi susulan yang lebih relevan, maka perlu ditinjau secara vertikal. Secara vertikal, sebaran episenter gempabumi susulan terkonsentrasi di sebelah tenggara-atas bidang patahan. Lokasi konsentrasi episenter gempabumi susulan ini berada di area peningkatan Coulomb stress yang nilainya berkisar antara 0-0,5 bar. Gambaran secara vertikal ditunjukkan pada Gambar 5.

Hasil ini juga bersesuaian dengan studi-studi sebelumnya yang menunjukkan bahwa peningkatan tegangan Coulomb dapat memicu gempabumi susulan. (Xie dkk., 2010) meneliti pola perubahan 
Coulomb stress oleh gempabumi Wenchuan dengan $\mathrm{Ms}=8,0$ serta pengaruhnya terhadap kejadian gempabumi susulan. Hasil yang didapatkan menunjukkan bahwa kejadian gempabumi susulan terletak pada area peningkatan Coulomb stress, bahkan dengan nilai konsistensi hingga 90\%. (Setiadi dkk., 2017) juga menunjukkan hal yang serupa. Sejumlah 64 gempabumi susulan dari gempabumi utama yang terjadi di Deli Serdang tanggal 16 Januari 2017 juga berlokasi pada area dengan perubahan Coulomb stress positif.

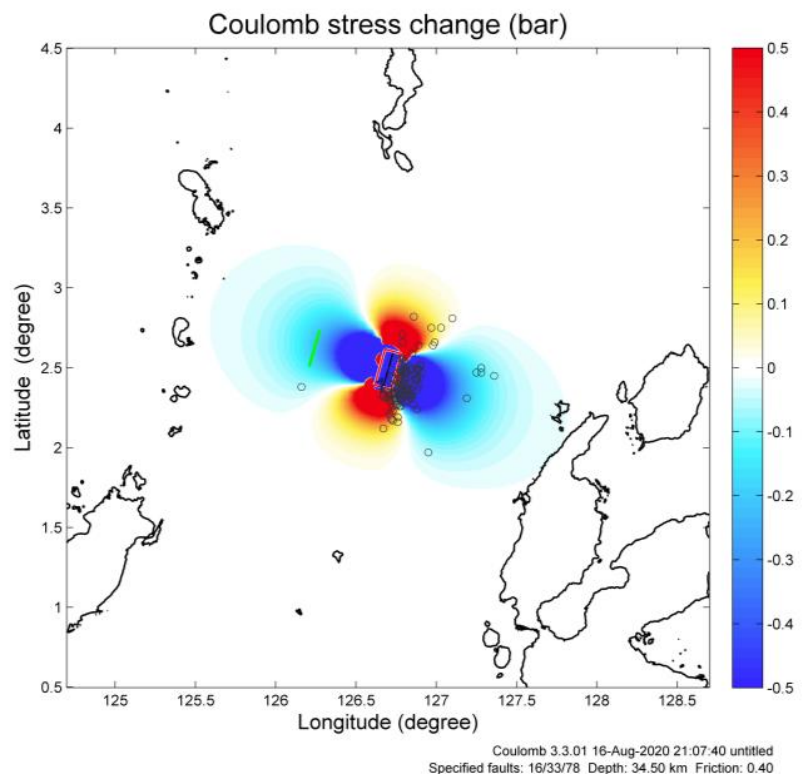

Gambar 4. Sebaran episenter gempabumi susulan (lingkaran hitam) yang di-overlay pada distribusi perubahan Coulomb stress gempabumi utama.

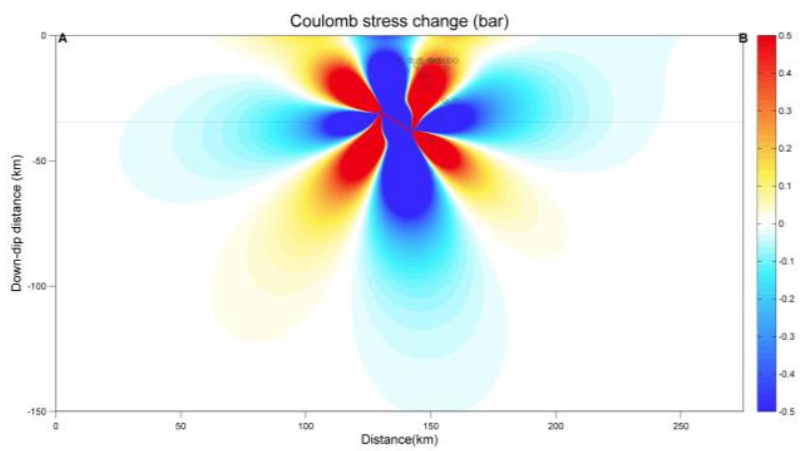

Gambar 5. Penampang melintang perubahan Coulomb stress dan sebaran episenter gempabumi susulan (lingkaran hitam)

Pada penelitian lainnya, perubahan Coulomb stress tidak hanya berhubungan dengan gempabumi susulan, tetapi juga bisa memicu aktivitas seismik di masa yang akan datang ( (S. Ardinsyah, 2014);(Madlazim, 2015)). (S. Ardinsyah, 2014) menjelaskan bahwa lokasi episenter gempabumi Bengkulu 12 September 2007 dengan Mw 8,5 terletak di area peningkatan Coulomb stress positif dari gempabumi Mw 7,9 tanggal 4 Juni 2000. Penelitian (Madlazim, 2015) juga mendapatkan hasil yang serupa, yaitu lokasi gempabumi Aceh 2 Juli 2013 dengan $\mathrm{Mw}$ 6,1 berkorelasi dengan perubahan Coulomb stress akibat gempabumi sebelumnya yang terjadi pada tanggal 21 Januari 2013 dengan magnitudo yang sama. Berdasarkan referensi tersebut maka perlu untuk dimonitoring lokasi peningkatan Coulomb stress akibat gempabumi Laut Maluku 7 Januari 2019 ini apakah juga mempengaruhi kejadian gempabumi di masa mendatang.

\section{PENUTUP}

\section{Kesimpulan}

Berdasarkan uraian yang telah dijabarkan sebelumnya, dapat ditarik dua poin kesimpulan dari penelitian ini, yaitu:

1. Distribusi perubahan Coulomb stress gempabumi 7 Januari 2019 di wilayah laut Maluku digambarkan dengan lobus negatif yang dominan terjadi di wilayah yang tegak lurus terhadap bidang sesar, sedangkan lobus positif dominan terjadi di ujung samping bidang sesar akibat pengaruh dari mekanisme sumber gempabumi yang dominan berupa sesar naik.

2. Lokasi sebaran episenter gempabumi susulan yang terkonsentrasi di sebelah tenggara-atas bidang patahan sebagian besar terletak di area peningkatan Coulomb stress dengan nilai berkisar antara 0 hingga 0,5 bar.

\section{Ucapan Terima Kasih}

Penulis menyampaikan terima kasih kepada civitas akademika Jurusan Fisika, FMIPA, Universitas Negeri Manado dan seluruh staf Stasiun Geofisika Manado yang telah mendukung penelitian ini baik secara moril maupun materiil. Penulis juga mengucapkan terima kasih kepada BMKG khususnya Stasiun Geofisika Manado yang telah 
mengijinkan penulis untuk memperoleh data parameter gempa susulan.

\section{DAFTAR PUSTAKA}

BMKG (2019), Earthquake Repository. Diambil 30 Juni 2019, http://repogempa.bmkg.go.id/repo_new/.

Dowling, N., Katakam, S. dan Narayanasamy, R. (2012), Mechanical behavior of materials: engineering methods for deformation, fracture, and fatigue.

Ekström, G., Nettles, M. dan Dziewoński, A.M. (2012), "The Global CMT Project 2004-2010: CentroidMoment Tensors for 13,017 Earthquakes", Physics of the Earth and Planetary Interiors, Vol.200-201, hal. 1-9. http://doi.org/10.1016/j.pepi.2012.04.002.

Harris, R.A. (1998), "Introduction to Special Section: Stress Triggers, Stress Shadows, and Implications for Seismic Hazard", Journal of Geophysical Research: Solid Earth, Vol.103, No.B10, hal. 24347-24358. http://doi.org/https://doi.org/10.1029/98JB015 76.

King, G.C.P., Stein, R.S. dan Lin, J. (1994), "Static Stress Changes and the Triggering of Earthquakes", Bulletin of the Seismological Society of America, Vol.84, No.3, hal. 935-953.

Madlazim, M. (2015), "COULOMB STRESS CHANGES DUE TO RECENT ACEH EARTHQUAKES", Jurnal Penelitian Fisika dan Aplikasinya (JPFA), Vol.5, hal. 9. http://doi.org/10.26740/jpfa.v5n1.p9-14.

S. Ardinsyah (2014), "Kajian jejak Coulomb static stress change dan lokasi gempa bumi signifikan daerah bengkulu (periode tahun 2000 - 2007)", Jurnal Ilmu Fisika, Vol.2, No.1.

Setiadi, T.A.P., Perdana, Y.H. dan Rohadi, S. (2017), "ANALISIS COULOMB STRESS GEMPA BUMI DELI SERDANG 16 JANUARI 2017", PROSIDING SEMINAR NASIONAL FISIKA (E-JOURNAL), Vol.6, hal. SNF2017-EPA-57-64. http://doi.org/10.21009/03.SNF2017.02.EPA.09

Sriyanto, S.P.D., Nurfitriani, N., Zulkifli, M. dan Wibowo, S.N.E. (2019), "PEMODELAN INUNDASI DAN WAKTU TIBA TSUNAMI DI KOTA BITUNG, SULAWESI UTARA BERDASARKAN SKENARIO GEMPABUMI LAUT MALUKU", GEOMATIKA, Vol.25, No.1, hal. 47-54. http://doi.org/10.24895/JIG.2019.25-1.959.

Toda, S., Stein, R.S., Sevilgen, V. dan Lin, J. (2011), Coulomb 3.3 Graphic-Rich Deformation and Stress-Change Software for Earthquake, Tectonic, and Volcano Research and Teaching--
User Guide. Diambil 23 Desember 2020, dari https://pubs.usgs.gov/of/2011/1060/.

USGS (2019), Earthquake Catalog. Diambil 8 Januari 2019, dari https://earthquake.usgs.gov/earthquakes/searc $\mathrm{h} /$.

USGS (2020), Search Earthquake Catalog. Diambil 25 Juni 2020, dari https://earthquake.usgs.gov/earthquakes/searc $\mathrm{h} / \mathrm{.}$

Weatherley, D K (2006), "Coulomb stress changes due to Queensland earthquakes and the implications for seismic risk assessment", Earthquake Engineering in Australia, Australian Earthquake Engineering Society, Melbourne, Diambil dari https://espace.library.uq.edu.au/view/UQ:1049 87.

Wells, D. dan Coppersmith, K. (1994), "New Empirical Relationships among Magnitude, Rupture Length, Rupture Width, Rupture Area, and Surface Displacement", Bulletin of the Seismological Society of America, Vol.84, hal. 974-1002.

Wu, J., Dongning, L., Yongjian, C. dan Heng, li (2015), "Stress triggering of the 2012 Sumatra Mw 8.2 earthquake by the 2012 Sumatra Mw 8.6 earthquake", Electronic Journal of Geotechnical Engineering, Vol.20, hal. 213-219.

Wu, J., Hu, Q., Li, W. dan Lei, D. (2016), Study on Coulomb Stress Triggering of the April 2015 M7.8 Nepal Earthquake Sequence. http://doi.org/https://doi.org/10.1155/2016/73 78920.

Xie, C., Zhu, Y., Lei, X., Yu, H. dan Hu, X. (2010), "Pattern of Stress Change and Its Effect on Seismicity Rate Caused by Ms8.0 Wenchuan Earthquake", Science China Earth Sciences, Vol.53, No.9, hal. 1260-1270. http://doi.org/10.1007/s11430010-4025-9.

Zhang, Q., Guo, F., Zhao, L. dan Wu, Y. (2017), "Geodynamics of Divergent Double Subduction: 3-D Numerical Modeling of a Cenozoic Example in the Molucca Sea Region, Indonesia", Journal of Geophysical Research: Solid Earth, Vol.122, No.5, hal. 3977-3998. http://doi.org/https://doi.org/10.1002/2017JB0 13991. 